\title{
OCCLUSAL TRAITS OF PRIMARY DENTITION AMONG CHILDREN VISITING A DENTAL HOSPITAL IN KATHMANDU, NEPAL
}

\author{
Shah $P^{1}$, Acharya J', Khanal $S^{1}$
}

${ }^{1}$ Department of Pedodontics and Preventive Dentistry, Nepal Medical College Teaching Hospital, Attarkhel, Gokarneshwor-8, Kathmandu, Nepal, ²Department of Global Heath Mahidol University,

\section{ABSTRACT}

Occlusion in deciduous dentition varies among children of different populations and races. Paucity of information in Nepalese literature provided the motive for this study. The objective of this study was to examine the occlusal traits of Primary Dentition among children aged 2-6 year old. A cross-sectional study comprising total of 307 children all having deciduous teeth were included in the study. The dentition was examined using a mouth mirror and explorer under illuminated light in Department of Pedodontics and the data was recorded. All the children were screened for molar and canine relationship, overjet, overbite, spaced and non-spaced dentition. Out of the total, Mesial step terminal plane (62\%-left; 58\%-right), Flush terminal (33\%-left; 36\% -right) and Distal step (5\%-left; 6\%-right) were seen. Most of the children had class I canine relation (83\%-left; 84\%-right), ideal overjet (68.4\%), overbite (63.1\%) and spaced dentition. Statistical significant difference was found among the gender with respect to overjet. Presence of spacing was more in maxilla than in mandible which was statistically significant. These findings suggested desirable occlusal characteristics and spacing in primary dentition. However, future longitudinal studies are required to examine whether the transition of these occlusal characteristics will lead to favorable outcome in permanent dentition.

\section{KEYWORDS}

Occlusion, primary dentition, molar relation, overjet, overbite

\section{CORRESPONDING AUTHOR}

Dr. Priyanka Shah

Lecturer,

Department of Pedodontics and Preventive Dentistry

Nepal Medical College Teaching Hospital,

Attarkhel, Gokarneshwor-8, Kathmandu, Nepal

Email: picu.shah@gmail.com 


\section{INTRODUCTION}

Occlusion in the primary dentition plays a significant role in determining the space for and occlusion in the succeeding permanent dentition..$^{1,2}$ Normal occlusion in primary teeth has the following characteristics: spacing between anterior teeth, primate spaces, low overjet and overbite, flush terminal plane molar relation, and ovoid arch form. ${ }^{3,4}$ The characteristic set of features of this dentition to a large extent lays the foundation for proper eruption and alignment of the succeeding dentition. Based on the observation of these key features of occlusion in the child's dentoalveolar system during the formative years, the characteristics of the permanent dentition occlusion can be predicted very well. Although the occlusion of the permanent dentition is largely influenced by the framework provided by the preceding primary dentition, its features vary among different populations and ethnic groups. ${ }^{5,6}$

Transition from normal deciduous dentition to normal permanent molar relationship brings alterations in the processes of differential growth in maxilla and mandible, which influence local changes in the dental arch. Disturbances in these normal processes can result in malocclusion, including crowding. Therefore, proper evaluation of normal characteristic features in primary dentition is important to be assessed with proper follow-up until the eruption of permanent successors to prevent potential problems. ${ }^{7}$ Crowding in primary dentition may cause malocclusion in permanent dentition. Generalized spacing of the primary teeth is a requirement for proper alignment of the permanent incisors. Contradictory findings documented in the literature worldwide, compounded by inadequate information on the primary dentition of Nepalese children, provided the sole motive for this study, the objective of which was to examine the occlusal traits of primary dentition among children aged 2-6 year old presenting in a private dental hospital in Kathmandu, Nepal.

\section{MATERIALS AND METHODS}

The study was a hospital based cross-sectional survey of 307 children of 2 to 6 -year-old who visited Department of Pedodontics and Preventive dentistry in Nepal Medical College Teaching Hospital, from March to June 2018. Guardians accompanying the children gave consent for the examination. The criterion for selecting the children consisted of choosing those having all of their primary teeth with no eruptions of permanent teeth whereas children with special health care needs (e.g., cleft lip and palate syndromes, medically and physically challenged), or having proximal caries affecting arch length and those who were not willing to participate in the oral examination were excluded from the study. All children were examined clinically in the dental OPD by a single trained clinician.

Oral examination was performed using a mouth mirror and explorer under illuminated light. All the participating children was screened for primary molar and canine relationship, overjet and overbite, spaced and non-spaced dentition.

The following parameters were recorded: ${ }^{8}$

\section{Primary molar relationship.}

a. Flush terminal plane: the distal surfaces of maxillary and mandibular primary second molars lie in the same vertical plane

b. Distal step: the distal surface of mandibular primary second molar is distal to that of the primary maxillary second molar

c. Mesial step: the distal surface of mandibular primary second molar is mesial to that of the maxillary primary second molar.

\section{Primary canine relationship.}

a. Class I: the tip of the maxillary canine is in the same vertical plane as the distal surface of the mandibular canine.

b. Class II: the tip of the maxillary primary canine tooth is mesial to the distal surface of the mandibular primary canine.

c. Class III: the tip of the maxillary canine is distal to the distal surface of the mandibular primary canine.

3. The degree of overjet was measured from the palatal surface of the mesial corner of the most protruded fully erupted maxillary incisor to the labial surface of the corresponding mandibular incisor and was recorded in millimeters.

a. Ideal: coverage of up to $1-2 \mathrm{~mm}$

b. Increased coverage: more than $2 \mathrm{~mm}$ of the mandibular incisors by maxillary incisors.

c. Edge-to-edge relation.

d. Anterior cross bite: was recorded when one or more maxillary incisors and canines occluded lingual to the mandibular incisors

4. The degree of overbite was graded according to the coverage of mandibular incisor by the most protruded fully erupted maxillary incisor.

a. Ideal: coverage of up to $1-2 \mathrm{~mm}$

b. Increased coverage: more than $2 \mathrm{~mm}$ of the mandibular incisors by maxillary incisors.

c. Decreased coverage: less than $1 \mathrm{~mm}$ of the mandibular incisors by maxillary incisors

d. Anterior open bite: negative overlap in the vertical plane. 


\section{The presence or absence of interdental spaces between primary teeth was noted, as was the presence or absence of primate spaces (spaces mesial to maxillary canine and distal to man- dibular primary canine).}

Ethical approval was obtained from Institutional Review Committee of Nepal Medical College. Written informed consent was obtained from a parent/ guardian of each child before the participation.

Data analysis was done using SPSS version 17.0. Descriptive statistics were obtained and frequency distribution were calculated. Pearson's Chi square test was used to test for association.

\section{RESULTS}

A total sample of 307 children was screened to assess the occlusal characteristics. Out of the total children who participated in the study, $50.2 \%$ were male and $49.8 \%$ were female (Table 1 ).

\section{Table 1: Distribution of children according to} gender

\begin{tabular}{|lcc|} 
& gender & ( \\
\hline Male & 154 & 50.2 \\
Female & 153 & 49.8 \\
\hline Total & 307 & 100 \\
\hline
\end{tabular}

Age distribution in the present study, was considered till 6 year old children who had complete set of the deciduous dentition. The age distribution is shown in Table 2.

The study revealed that the most common molar relationship in all the age group was mesial step followed by flush terminal and then distal step. More than half of the children had a mesial step terminal plane $(62.0 \%$ for left molars, and $58.0 \%$ for right molars), and about one third had flush terminal (33.0\% for left molars and 36.0\% for right molars) whereas distal step was seen in (5\% left molars and $6 \%$ right molars) as shown in Table 3. There was statistically significant difference in molar relation for left side among males and females $(p<0.05)$ (Table 4).

Among the total children, class I canine relationship was present in $(83.0 \%$ for left canines, and $84.0 \%$ for right canines), followed by class II (11.0\% for left canines, and $9.0 \%$ for right canines) and class III ( $7 \%$ for left canines, and $6.0 \%$ for right canines). Statistical significant difference was found among the gender with respect to canine relation for right side $(\mathrm{p}<0.05)$ (Table 4).

In the maxillary arch, both canine space and interdental space was present in $61.6 \%$ of the population however in mandibular arch the presence of both canine and interdental space was found to be in just $29.6 \%$ of population. Both canine space and interdental space was absent in $21.0 \%$ in maxillary arch and $52.0 \%$ in mandibular arch. Presence of only canine space was present in $12.0 \%$ in maxilla and $5.0 \%$ in mandible whereas interdental spaces between incisors and lateral was seen in $5.0 \%$ in maxilla and $13.0 \%$ in mandible (Table 5). Presence of spacing was more in maxilla than in mandible which was statistically significant $(p<0.05)$ (Table 6).

An ideal overjet was observed among $68.4 \%$ children followed by edge to edge bite (15.3\%) and increased overjet $(9.4 \%)$, while the least frequent type was reverse overjet (5.2\%) (Table 7$)$. The evaluation

\begin{tabular}{|lccc|}
\hline & Table 2: Distribution of children according to age & \\
\hline Age (months) & Male $\mathbf{n}(\%)$ & Female $\mathbf{n}(\%)$ & Total n (\%) \\
$24-36$ & $9(60 \%)$ & $6(40 \%)$ & $15(4.9 \%)$ \\
$37-48$ & $26(51 \%)$ & $25(49 \%)$ & $51(16.6 \%)$ \\
$49-60$ & $42(51.2 \%)$ & $40(48.8 \%)$ & $82(26.7 \%)$ \\
$61-72$ & $77(48.4 \%)$ & $82(51.6 \%)$ & $159(51.8 \%)$ \\
\hline
\end{tabular}

Table 3: Molar relation

\begin{tabular}{|c|c|c|c|c|c|c|}
\hline \multirow{2}{*}{ Age (months) } & \multicolumn{2}{|c|}{ Flush Terminal } & \multicolumn{2}{|c|}{ Mesial step } & \multicolumn{2}{|c|}{ Distal step } \\
\hline & Right n (\%) & Left n (\%) & Right n (\%) & Left n (\%) & Right n (\%) & Left n (\%) \\
\hline $24-36$ & $4(26.7)$ & $6(40.0)$ & $10(66.7)$ & $8(53.3)$ & $1(6.7)$ & $1(6.7)$ \\
\hline $37-48$ & $21(41.2)$ & $19(37.3)$ & $26(51)$ & $28(54.9)$ & $4(7.8)$ & $4(7.8)$ \\
\hline $49-60$ & $29(35.4)$ & 27 ( 32.9$)$ & $46(56.1)$ & $52(63.4)$ & $7(8.5)$ & $3(3.7)$ \\
\hline $61-72$ & $56(35.2)$ & $49(30.8)$ & $98(61.6)$ & $103(64.8)$ & $59(3.1)$ & $7(4.4)$ \\
\hline Total (\%) & $110(35.8)$ & $101(32.9)$ & $180(58.6)$ & $191(62.2)$ & $17(5.5)$ & $15(4.9)$ \\
\hline
\end{tabular}


Table 4: Distribution of Occlusal variants according to Gender

Gender

Male

Female

p

Flush
terminal Mesial step $\quad$ Distal Step $\begin{gathered}\text { Flush } \\ \text { terminal }\end{gathered} \begin{gathered}\text { Mesial } \\ \text { Step }\end{gathered}$ Distal Step

Molar
relation Right Left Right Left Right Left Right Left Right Left Right Left < 0.05

$\begin{array}{cccccccccccc}51 & 43 & 90 & 98 & 13 & 13 & 59 & 58 & 90 & 93 & 4 & 2 \\ \text { Class I } & \text { Class II } & \text { Class III } & \text { Class I } & \text { Class II } & \text { Class III } & \end{array}$

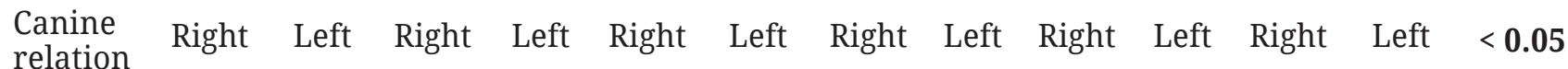

$\begin{array}{lllllllllllllll}\text { relation } & 121 & 129 & 26 & 18 & 7 & 7 & 134 & 128 & 8 & 11 & 11 & 14 & \text { Right }\end{array}$

\begin{tabular}{|c|c|c|c|c|c|c|c|c|}
\hline \multirow{2}{*}{$\begin{array}{l}\text { Age } \\
\text { (months) }\end{array}$} & \multicolumn{2}{|c|}{ Both Present } & \multicolumn{2}{|c|}{ Both absent } & \multicolumn{2}{|c|}{$\begin{array}{l}\text { Only canine space } \\
\text { present }\end{array}$} & \multicolumn{2}{|c|}{$\begin{array}{l}\text { Only Interdental } \\
\text { space present }\end{array}$} \\
\hline & Maxilla & Mandible & Maxilla & Mandible & Maxilla & Mandible & Maxilla & Mandible \\
\hline $24-36$ & 10 & 6 & 4 & 8 & 1 & 1 & 0 & 0 \\
\hline $37-48$ & 34 & 16 & 10 & 24 & 6 & 2 & 1 & 9 \\
\hline $49-60$ & 46 & 23 & 20 & 43 & 11 & 5 & 5 & 11 \\
\hline $61-72$ & 99 & 46 & 31 & 85 & 20 & 9 & 9 & 19 \\
\hline Total (\%) & $\begin{array}{c}189 \\
(61.6 \%)\end{array}$ & $\begin{array}{c}91 \\
(29.6 \%)\end{array}$ & $\begin{array}{c}65 \\
(21.2 \%)\end{array}$ & $\begin{array}{c}160 \\
(52.1 \%)\end{array}$ & $\begin{array}{c}38 \\
(12.4 \%)\end{array}$ & $\begin{array}{c}17 \\
(5.5 \%)\end{array}$ & $\begin{array}{c}15 \\
(4.9 \%)\end{array}$ & $\begin{array}{c}39 \\
(12.7 \%)\end{array}$ \\
\hline
\end{tabular}

of overbite showed that $63.1 \%$ children had ideal overbite, $15.0 \%$ had increased overbite while $1.6 \%$ had anterior open bite, and $14.7 \%$ had reduced overbite (Table 8). Statistical significant difference was found among the gender with respect to overjet $(p<0.05)$ (Table 7). while no significance was found with regard to overbite (Table 8).

\begin{tabular}{|llll|}
\hline \multicolumn{4}{|c|}{ Table 6: Space in maxilla and mandible } \\
\hline Arch & Spaced & Non-spaced & P-value \\
Maxilla & 242 & 65 & \\
Mandible & 147 & 160 & $<\mathbf{0 . 0 5}$ \\
Total & $\mathbf{3 0 7}$ & $\mathbf{3 0 7}$ & \\
\hline
\end{tabular}

\section{Table 7: Distribution of Overjet variations according to Gender}

Overjet

Gender

Male

Female

Ideal Increased Edge to edge

Anterior

others Total P-value

Total (\%) $\quad 210(68.4) \quad 29(9.4) \quad 47(15.3)$

crossbite

154

153

$<0.05$

\section{Table 8: Distribution of Overbite variations according to Gender}

Overbite

Ideal Increased Decreased Anterior Open bite Others Total

Gender

Male

Female

$94 \quad 23$

29

99

23

17

$16(5.2)$

5 (1.6) $\quad 307$

Total (\%)

$193(63.1) \quad 46(15.0) \quad 46(14.7)$

5 (1.6)

17 (5.6) $\quad 307$ 


\section{DISCUSSION}

Various studies have been conducted to document the characteristics of the primary dentition in different populations. ${ }^{9,10}$ Early recognition of conditions predisposing young children to malocclusions is in the hands of primary care providers who are general practitioners and the pediatric dentist. ${ }^{11}$ It is important that conditions that predispose to develop a malocclusion like crowding, open bite, crossbite be detected early in the primary dentition so that early interceptive procedure can be applied to prevent its further consequences. So, early educational programs and parental seeking of dental care in young age should be fostered so that the children who are at risk especially those with crossbite, crowding gets early treatment and will get additional benefits if kept on regular follow up.

The study revealed that the most common molar relationship in all the age group was mesial step followed by flush terminal and then the distal step. Mesial step terminal plane was seen in $(62.0 \%$ for left molars, and $58.0 \%$ for right molars), flush terminal was seen in $(33.0 \%$ for left molars and $36.0 \%$ for right molars) whereas distal step was seen in (5.0\% left molars and $6.0 \%$ right molars). On similar note, several other studies have also shown that mesial step relation recorded highest followed by flush terminal plane and distal step. In one study done in Indian preschool children, there was highest occurrence of mesial step molar relation (57.3\%) followed by flush terminal plane (31.1\%) and then the distal step molar relation (11.7\%). ${ }^{7}$ Similar results were also obtained in studies done in Jordanian children. ${ }^{6}$ Analogous observations were also found in studies done in American and Indian population..$^{9,10}$ On contradiction, results obtained by another study showed that flush terminal plane $(88.3 \%)$ is more commonly seen followed by distal step $(7.3 \%)$ and then mesial step molar relation $(4.4 \%){ }^{8}$ Similar finding was also noted in several studies. ${ }^{11-17}$

Considering canine relation, class I canine relationship was present in (83.0\% for left canines, and $84.0 \%$ for right canines), followed by class II (11.0\% for left canines, and 9.0\% for right canines) and class III ( $7.0 \%$ for left canines, and 6\% for right canines). One of the study done in Wardha District of India, had also concluded that among the canine relation, Class I (47.2\%) showed highest value followed by Class II (42.8\%) and Class III (9.9\%). ${ }^{7}$ These findings were in agreement with other studies also. ${ }^{18,19,6}$ Contrarily another concluded that among the canine relation, Class I (90.1\%) showed peak value succeeded by Class III (7.4\%), and Class II $(2.5 \%){ }^{20}$ Contradictory findings were reported in Finnish children among whom class II relation $(52.4 \%)$ was the most prominent followed by class I (46.1\%) and class III (1.5\%). ${ }^{21}$

The most frequent spacing in the maxillary arch was both canine space and interdental space which was present in $61.6 \%$ of the population however in mandibular arch the presence of both canine and interdental space was found to be in just 29.6\% of population. The absence of spacing was more prevalent in the mandible than in the maxilla which was statistically significant. These findings indicated that in normal deciduous dentition spacing appear to be more common feature even though they were few subjects devoid of any spacing. A study conducted on 3-6 years school children in Gujarat concluded that non-spaced dentition was less common in school children when compared to spaced dentition this finding is analogous with our study. ${ }^{3}$ In our study, Primate spaces were frequently found in the maxilla than mandible, this was similar to study done in Indian and Jordanian population. ${ }^{3,6}$

The results of our study revealed ideal overjet in $68.4 \%$ children, increased overjet in $9.4 \%$, edge-toedge bite in $15.3 \%$, and anterior crossbite in $5.2 \%$ of the children. This finding is consistent with Nigerian children who demonstrated ideal overjet in $68.6 \%$, increased overjet in 14.7\%, edge-to-edge bite in 9.7\%, and reverse bite in $7.0 \%{ }^{19}$ Similar observation in which ideal overjet was predominant was also seen in studies done in Chinese, ${ }^{22}$ Saudi $^{18}$ and Dravidian population. ${ }^{16}$ In a study done in Dravidian children, Anterior crossbite was observed in $0.5 \%$ children, and edge-to-edge bite in $4.5 \%$ of the children which was less than our investigation. Anterior crossbite was seen in $2.0 \%$ of children in Chennai. ${ }^{23}$

Evaluation of overbite showed that $63.1 \%$ children had ideal overbite, $15.0 \%$ had increased overbite while $1.6 \%$ had anterior open bite, and $14.7 \%$ had reduced overbite. Our finding is akin to study done in Dravidian population in which majority (72.7)\% of the population had ideal overbite and $1.5 \%$ of population had anterior open bite. ${ }^{16}$ Anterior open bite was not seen in a study done in Indian children in Udaipur ${ }^{10}$ whereas $8 \%$ of children had anterior open bite in a population of Tanzanian and Finnish children. ${ }^{24}$ In a study done in Jordan, anterior open bite was seen in $5.7 \%$ of population.

Most of the Nepali children had Mesial step molar relation, Class I canine relation, ideal overjet and overbite and spaced dentition about $2.0 \%$ of the children had anterior crossbite and $1.6 \%$ had open bite. These findings suggest desirable occlusal pattern. Lower prevalence of open bite is suggestive of lower prevalence of abnormal sucking habits in Nepali population. However, further longitudinal studies are required to observe the changes in occlusal pattern from primary to permanent dentition.

\section{REFERENCES}

1. Infante P. An epidemiologic study of deciduous molar relations in preschool children. J Dent Res 1975; 54: 723-7.

2. Foster T, Grundy M. Occlusal changes from primary to permanent dentition. Brit Dent Orthod 1986; 13: 187-93. 
3. Joshi M, Makhija P. Some observations on spacing in the normal deciduous dentition of 100 Indian children from Gujarat. Brit J Orthod 1984; 11: 75-9.

4. Motayamand K, Elbardissy A. Occlusal characteristics of primary dentition in preschool Egyptian children. Cairo Dent J 2007; 23: 217-26.

5. Foster T, Hamilton M. Foster TD, Hamilton MC. Occlusion in the primary dentition, study of children at 2 1/2 to 3 years of age. Brit Dent J 1969; 126: 76-9.

6. Abu Alhaija E, Qudeimat M. Occlusion and tooth/ arch dimension in primary dentition of preschool Jordanian children. Int'l J Paediatr Dent 2003; 13: 230-9.

7. Bahadure RN, Thosar N, Gaikwad R. Occlusal traits of deciduous dentition of preschool children of Indian children. Contemp Clin Dent 2012; 3: 443-7.

8. Yilmaz Y, Gurbuz T, Simsek S et al. Primary Canine and Molar Relationships in Centric Occlusion in Three to Six Year-Old Turkish Children: A CrossSectional Study. J Contemp Dent Pr 2007; 7: 59-66.

9. Penido S, Carrel R, Ed M et al. Occlusal assessment of a 3-5 year population. Pediatr Dent 1979; 1: 1048.

10. Hegde S, Panwar S, Bolar DR et al. Characteristics of occlusion in primary dentition of preschool children of Udaipur, India. Eur J Dent 2012; 6: 51-5.

11. Shavi GR, Hiremath N V, Shukla R et al. Prevalence of Spaced and Non-Spaced Dentition and Occlusal Relationship of Primary Dentition and its Relation to Malocclusion in School Children of Davangere. J Int'l Oral Health 2015; 7: 75-8.

12. Fernandes S, Gordhanbhai Patel D, Ranadheer E et al. Occlusal Traits of Primary Dentition among PreSchool Children of Mehsana District, North Gujarat, India. J Clin Diagn Res 2017; 11: ZC92-6.

13. Bhayya DP, Shyagali TR, Dixit UB et al. Study of occlusal characteristics of primary dentition and the prevalence of maloclusion in 4 to 6 years old children in India. Dent Res J (Isfahan) 2012; 9: 61923.
14. Farsi NM, Salama FS. Characteristics of primary dentition occlusion in a group of Saudi children. Int'l J Paediatr Dent 1996; 6: 253-9.

15. Khan R, Singh N, Govil S et al. Occlusion and occlusal characteristics of primary dentition in North Indian children of East Lucknow region. Eur Arch Paediatr Dent 2014; 15: 293-9.

16. Vegesna M, Chandrasekhar R, Chandrappa V. Occlusal Characteristics and Spacing in Primary Dentition: A Gender Comparative Cross-Sectional Study. Int'l Sch Res Not 2014; 1-7.

17. Srinivasan D, Loganathan D, Kumar SS et al. An evaluation of occlusal relationship and primate space in deciduous dentition in Kancheepuram District, Tamil Nadu, India. J Pharm Bioall Sci 2017; 9: 45-9.

18. Farsi M, Salama F. Characteristics of primary dentition occlusion in a group of Saudi children. Int'l J Paediatr Dent 1996; 6: 253-9.

19. Otuyemi O, Sote E, Isiekwe $\mathrm{M}$ et al. Occlusal relationship and spacing or crowding of teeth in the dentitions of 3-4 year-old Nigerian children. Int'l J Paediatr Dent 1997; 7: 155-60.

20. Baidas L. Occlusion characteristics of the primary dentition by age in a sample of Saudi preschool children. Pak Oral Dent J 2010; 30: 425-31.

21. Keski-Nisula K, Lehto R, Lusa V et al. Occurrence of malocclusion and need of orthodontic treatment in early mixed dentition. Am J Orthod Dentofac Orthop 2003; 124: 631-8.

22. Zhang S, Lo ECM, Chu CH. Occlusal features and caries experience of Hong Kong chinese preschool children: A cross-sectional study. Int'l J Environ Res Public Health 2017; 14: 621. https://doi.org/10.3390/ ijerph14060621

23. Anitha X, Asokan S. Occlusion characteristics of preschoolers in Chennai: a cross-sectional study. $J$ Dent Child 2013; 80: 62-6.

24. Kerosuo H. Occlusion in primary and early mixed dentition in a group of Tanzanian and Finnish children. J Dent Child 1990; 57: 293-8. 